\title{
Monitoring, Estimation and Design of Prevention System on Transport
}

\author{
Vasiliy V. Kovalenko*, Nikolay F. Bulgakov, \\ Elena G. Mahova and Pavel S. Latkin \\ Siberian Federal University \\ 79 Svobodny, Krasnoyarsk, 660041, Russia
}

Received 25.12.2014, received in revised form 09.04.2015, accepted 18.08.2015

The peculiarities of the development and practical application of information-analytical system of monitoring, evaluation and design prevention system on transport. The use of complex analytical programs for electronic computing machines (computers) contributes to the improvement of the management prevention system of transport vehicle (TV) companies.

Keywords: reliability, prevention, assessment of reliability, maintenance management, information technology, prevention.

DOI: $10.17516 / 1999-494 X-2015-8-7-941-947$.

\section{Мониторинг, оценка и проектирование системы профилактики на транспорте}

В.В. Коваленко, Н.Ф. Булгаков, Е.Г. Махова, П.С. Латкин

Сибирский федеральный университет Россия, 660041, Красноярск, пр. Свободный, 79

Рассмотрень особенности разработки и практического применения информационноаналитической системы мониторинга, оценки и проектирования системы профилактики на транспорте. Использование комплекса информационно-аналитических программ для электронно-вычислительных машин (ЭВМ) способствует совершенствованию управления системой профилактики транспортных средств (TC) на транспортных предприятиях.

Ключевые слова: надежность, профилактика, оценка надежности, управление техническим обслуживанием, информационные технологии, система профилактики.

Для транспортных средств (ТC) заводом-изготовителем разработаны мероприятия, направленные на устранение неисправностей и отказов, заключающиеся в применении системы

(C) Siberian Federal University. All rights reserved

* Corresponding author E-mail address: kovvas-atf@mail.ru 


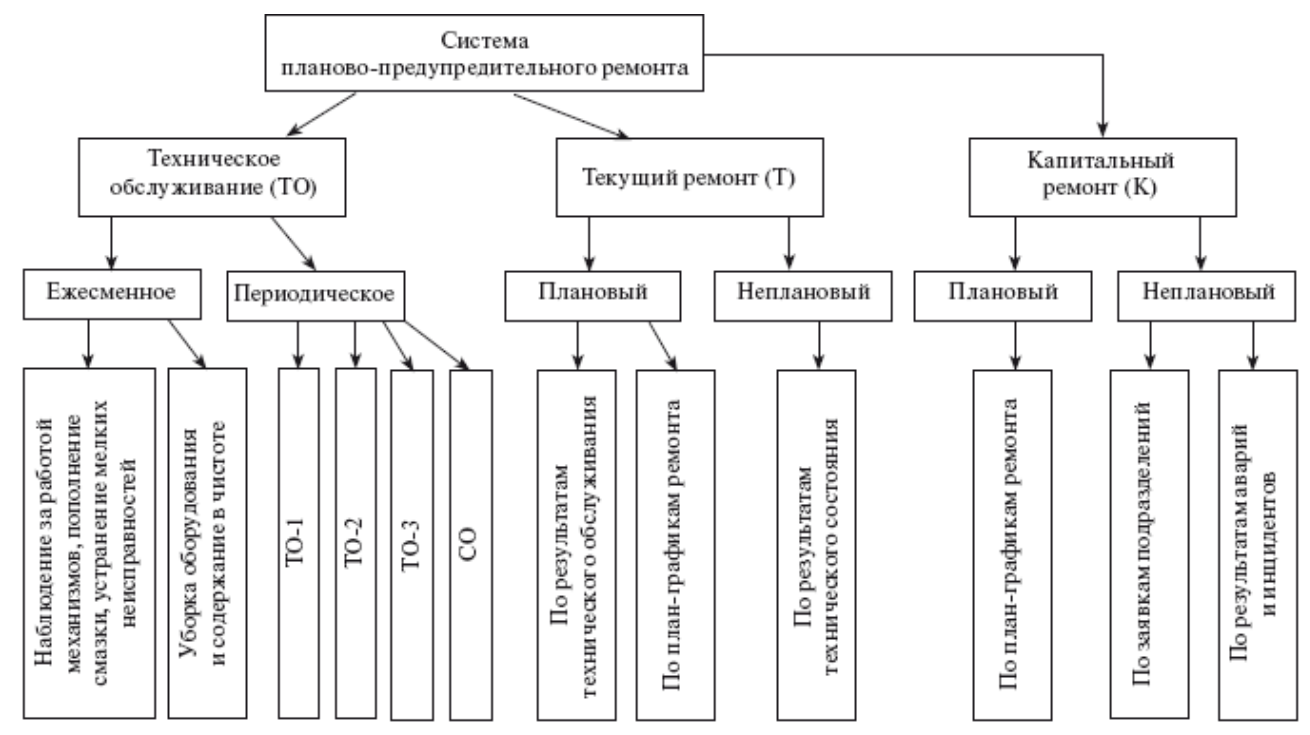

Рис. 1. Система планово-предупредительного ремонта по ГОСТ 18322-78

технического обслуживания и ремонта (ТО и Р). Применяемая система ТО и Р (рис. 1) предусматривает выполнение планового обслуживания по периодичности (например, на автомобильном транспорте ТО-1 и ТО-2) и текущий ремонт по потребности. При этом на практике возникают ситуации, когда плановые работы выполняются в полном объеме, а отказ и сходы ТС с линии не сокращаются. Это приводит к тому, что возникают очереди на обслуживание ТC, возрастает потребность в персонале для обслуживания ТС, увеличиваются затраты на поддержание работоспособного состояния ТС. Рост затрат на систему ТО и Р обусловлен износом ТC, дублированием заявок и расходуемых элементов при обслуживании ТС (из-за незнания вероятностного метода прогнозирование отказов) и использованием некачественных элементов.

Современные исследования, посвященные вопросам совершенствования системы обслуживания ТС и автоматизации управления транспортным предприятием, изложены в трудах: Н.Ф. Булгакова [1, 2], И.М. Блянкинштейна [3, 4], А.С. Кузнецова [5], А.С. Полякова [6], В.Н. Катаргина [7] и др. В настоящее время хранящаяся в транспортных предприятиях информация об отказах ТС носит фрагментарный характер и не в полной мере используется для расчета показателей эксплуатационной надежности и их прогнозирования. Решением сложившейся ситуации является применение современных инновационных методов совершенствования системы ТО и Р и создание системы профилактики ТС. Профилактика ТС - комплекс технологических, организационных и информационных мероприятий, направленных на обнаружение, устранение и предупреждение неисправностей и отказов. Для совершенствования системы профилактики ТС необходимо развивать системы информационного, нормативного, организационного и математического обеспечения на предприятии. Информационное обеспечение существенно упрощает процессы мониторинга, оценки показателей надежности и разработку ступеней системы профилактики ТС, что позволяет принимать своевременные и обоснованные управленческие решения по ТО и ремонту ТС. Однако существующие средства автоматизации процессов мониторинга, оценки показателей надежности и проектирования ступеней профилактики 
элементов ТС слабо развиты и работают автономно, без взаимодействия с другими программными продуктами. Для решения сложившейся ситуации предлагается специализированное программное обеспечение для работы на транспортном предприятии.

Решение проблемы. В методических указаниях РД 50-204-87 определены общие требования к сбору и обработке информации о надёжности изделий в эксплуатации, которые применительно к ТС отражены в заявочно-ремонтном листке (ЗРЛ). На основе данных из ЗРЛ инженеры производственно-технического отдела ТП формируют: план-графики на прохождение плановых обслуживаний ТС, отчеты о расходе запасных частей при восстановлении работоспособного состояния ТС и другие отчеты, необходимые для принятия решений при обслуживании ТС. Для более быстрой обработки данных транспортные предприятия используют программные продукты, позволяющие создавать и хранить документы, функционирующие в системе технического обслуживания и ремонта ТС.

На текущий момент для автоматизации обработки данных на ТП существует ряд программных продуктов: «1С: Управление производственным предприятием 8», программа «Контроль и учет автотранспорта», пакет программ «AutoSoft» (АвтоПредприятие, АвтоКаталог, АвтоМастерская), «ELSA», «MT DMSL» и др. Основными недостатками (ограничениями) представленных программ являются: стоимость; ограниченность функций (в основном это только сбор и хранение данных); сложность в управлении (требуется как поддержка разработчиками удаленно, так и управление программой программистом или администратором, также требуются высококвалифицированные специалисты при работе с программным продуктом). Для подобных программных продуктов необходим большой объем доработок, что соизмеримо с разработкой собственных информационных средств поддержки планирования и управления. Также сбор информации о выполненных работах и израсходованных элементах при обслуживании ТС затруднителен и возможен только через отдел транспортного предприятия, например, производственно-технический отдел или отдел технического контроля, что существенно влияет на продолжительность простоя ТС в обслуживании.

Авторским коллективом кафедры «Транспорт» Сибирского федерального университета была разработана и внедрена на муниципальное автотранспортное предприятие г. Красноярска программа для ЭВМ «Модель автоматизированного управления информационным обеспечением системы профилактики». Данная программа позволяет обеспечивать непрерывный мониторинг технических показателей эксплуатации ТС (интерфейс программы представлен на рис. 2) и производить анализ получаемых данных.

Разработанная для ЭВМ программа не только позволяет консолидировать информацию, но и обеспечивает персонал данными для оценки интенсивности отказов, формирования вариационных рядов на отказ элементов ТС. Для совершенствования системы ТО и Р предлагается внедрение не только программы для мониторинга показателей надежности ТС, но и программ по оценке показателей надежности и разработке разновидностей технических воздействий системы профилактики ТС [8-10]. В комплексе программы образуют информационную систему профилактики ТС (ИС).

Аналитическая программа «Оценка показателей надежности техники» решает задачи анализа показателей надежности и представляет данные по их изменению во времени или наработке. Интерфейс окна программы представлен на рис. 3. При этом в программе имеется воз-

$$
-943-
$$




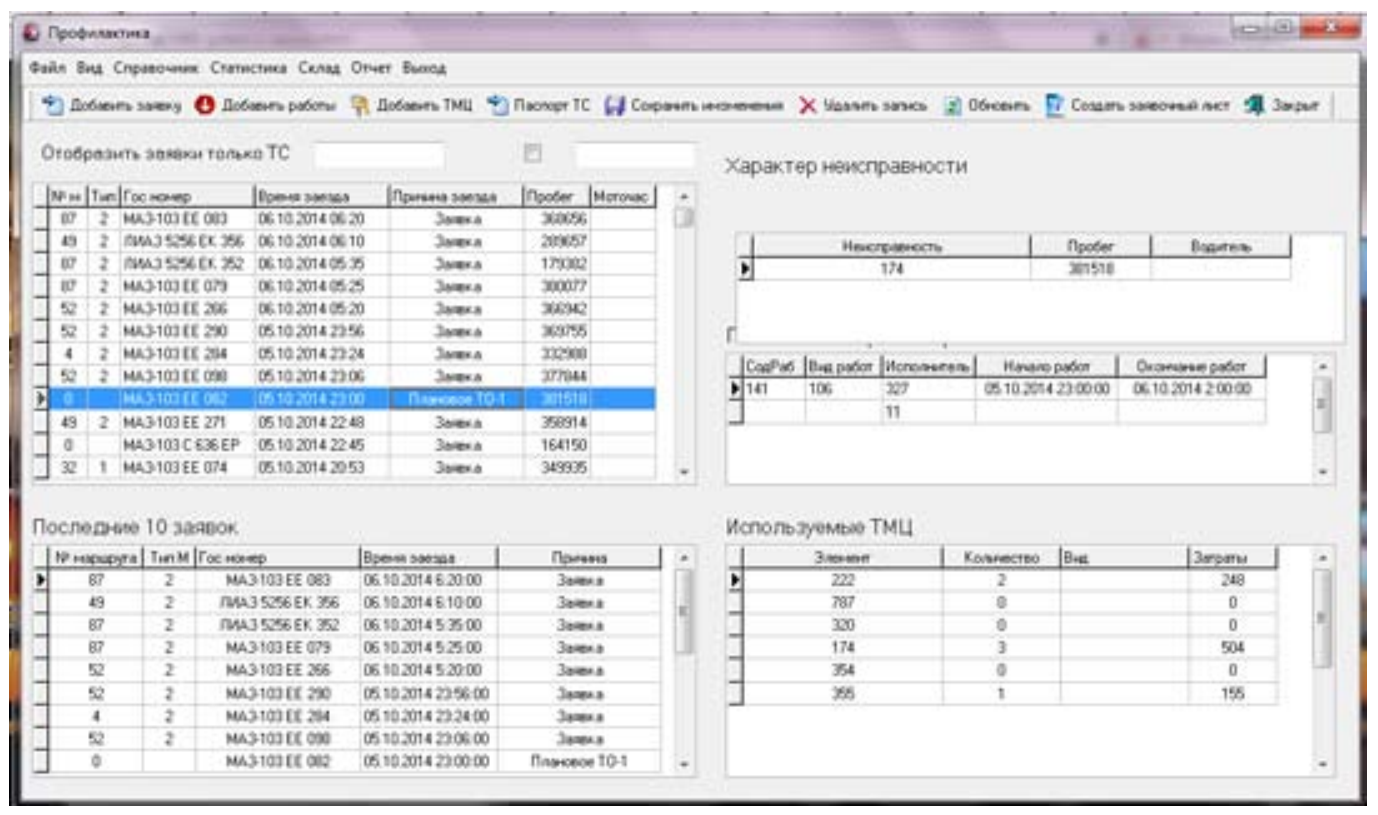

Рис. 2. Интерфейс программы «Модель автоматизированного управления информационным обеспечением системы профилактики»

можность сохранить расчет показателей надежности и при необходимости его редактировать $[1,2,9]$.

Аналитическая программа «Проектирование регламента системы профилактики техники» решает задачу проектирования дополнительных ступеней профилактики на основе показателей надежности элементов ТС (интерфейс окна программы изображен на рис. 4). Математический аппарат по проектированию ступеней и разновидностей системы профилактики ТС рассмотрен в работах Н.Ф. Булгакова и др. $[1,2]$.

Разработанная ИС позволяет в полном объеме организовать сбор, анализ, хранение данных и прогнозирование разновидностей технических воздействий на ТС. Основными задачами, решаемыми ИС, являются:

- у учет текущих и плановых обслуживаний ТС;

- учет израсходованных комплектующих элементов ТС;

- учет наработки отказываемых элементов ТС;

- планирование плановых работ по обслуживанию;

- оценка показателей надежности элементов ТС;

- разработка и учет мероприятий по недопущению отказов;

- отчетность по выполненным работам и израсходованным элементам ТС;

- прогнозирование выполнения работ по обслуживанию элементов ТС;

- формирование вариационных рядов на элементы ТС;

- формирование разновидностей технических воздействий ТС.

Взаимодействие информационных программ между собой отображено на рис. 5. Структура ИС и каждой из программ состоит из следующих подсистем: 


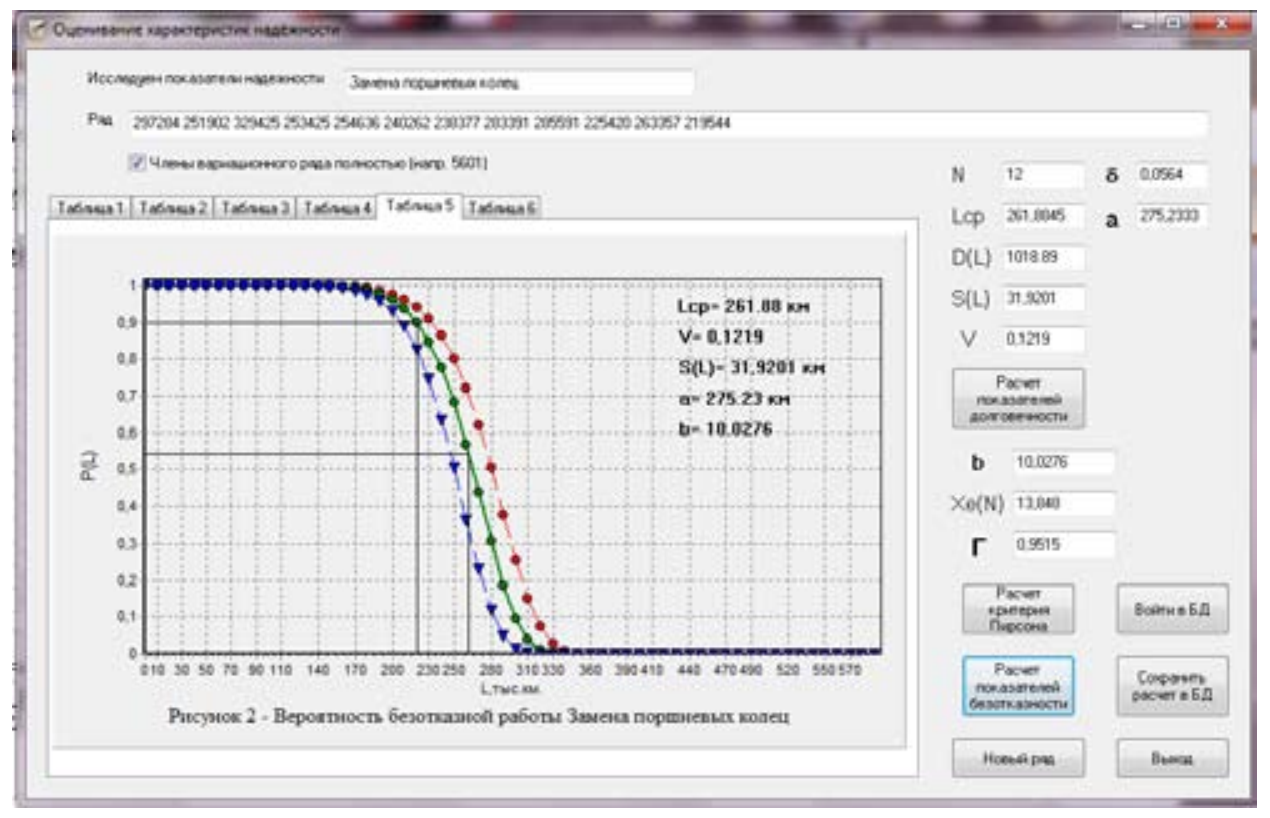

Рис. 3. Интерфейс программы «Оценка показателей надежности техники»

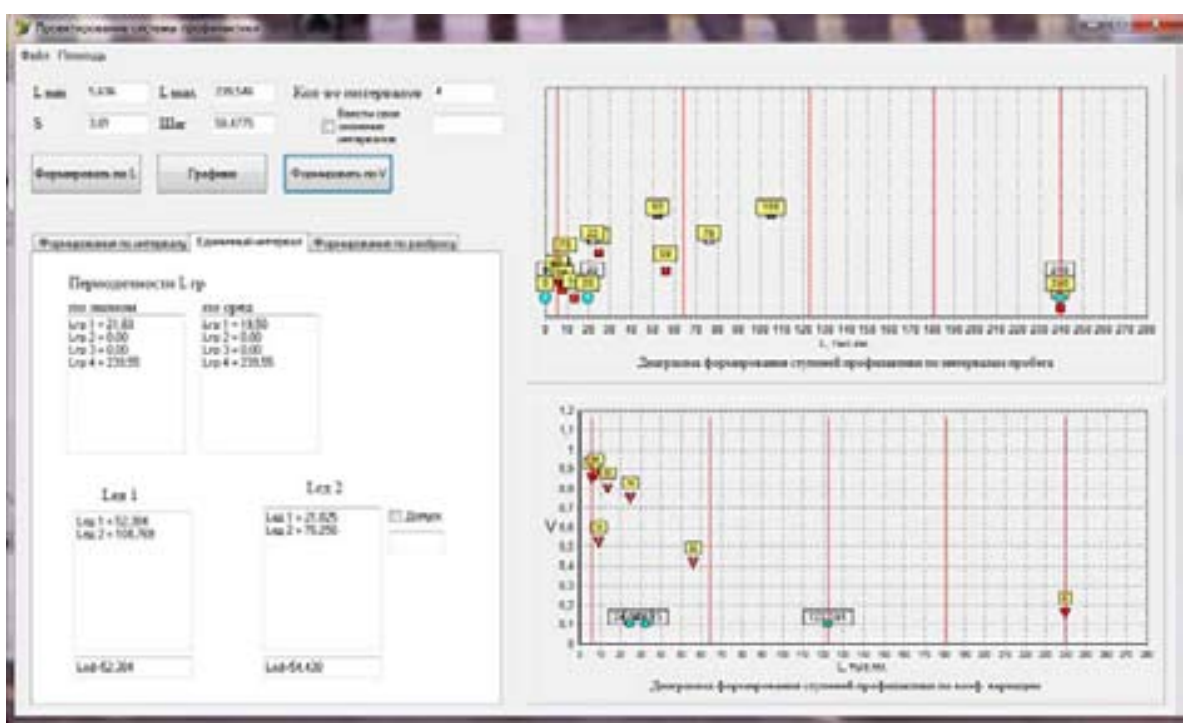

Рис. 4. Интерфейс программы «Проектирование регламента профилактики»

1) подсистема сбора данных, которая собирает и проводит предварительную обработку данных из различных источников (ЗРЛ, диагностические карты и др.);

2) подсистема хранения и выборки данных, организующая данные с целью их выборки по критериям;

3) подсистема анализа данных, которая группирует и выполняет вычислительные функции; 


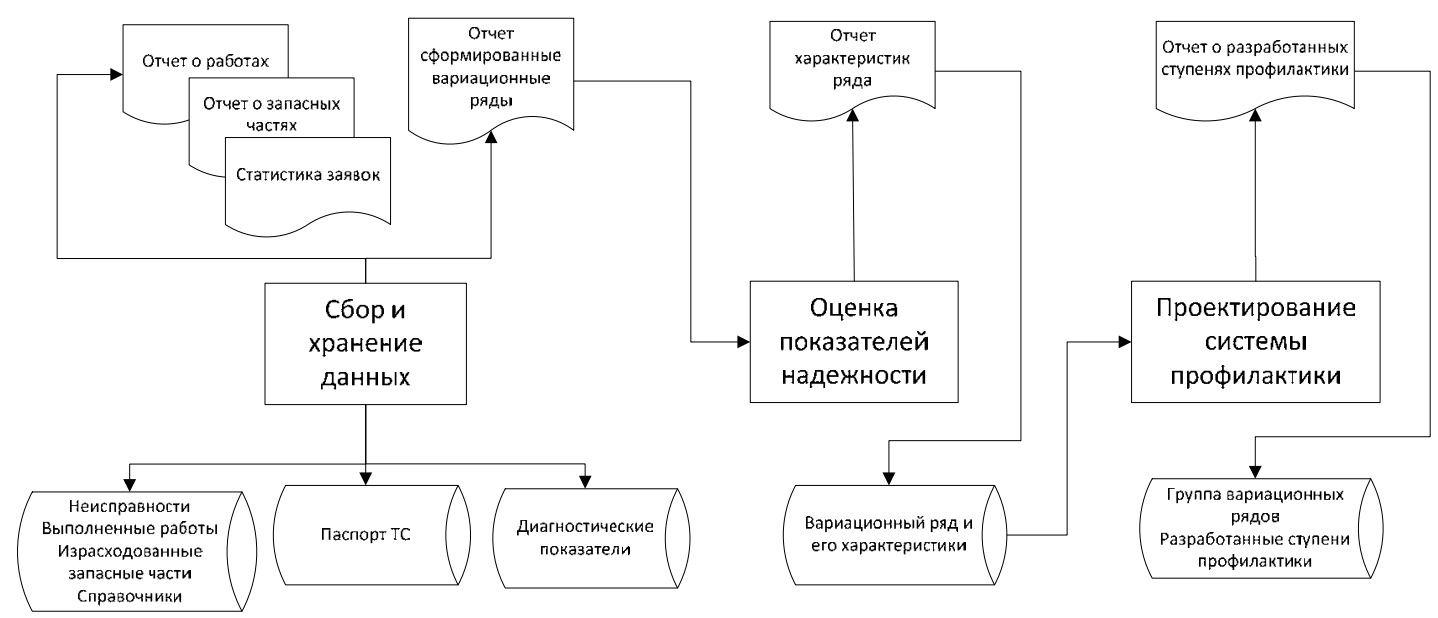

Рис. 5. Схема взаимодействия программ

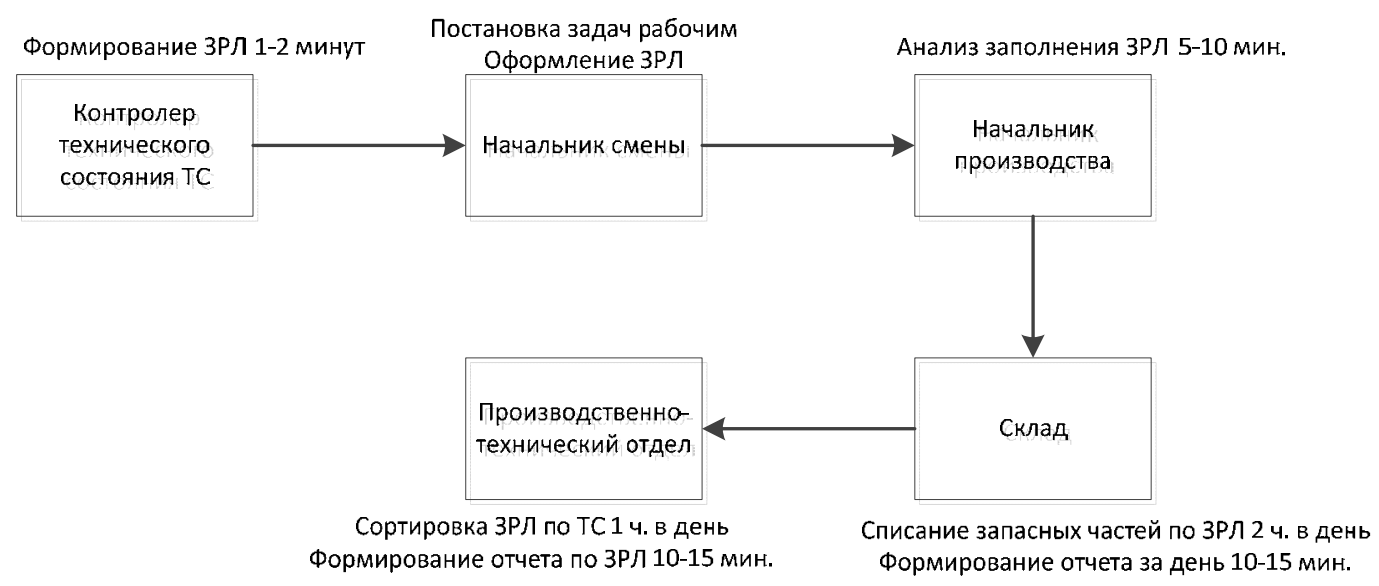

Рис. 6. Движение заявочно-ремонтного листка на предприятии до внедрения ИС

4) подсистема вывода, которая отображает базу данных или ее часть и передает данные в другие форматы таблиц, например в MO Excel.

Для работы в ИС на предприятии были сформированы автоматизированные рабочие места (APM): механика технического состояния ТС, начальника ремонтно-мехнических мастерских и начальника смен. Также был проведен анализ движения заявочно-ремонтного листка (ЗРЛ) до внедрения ИС (рис. 6).

До «конечного» пункта (архива) документы доходят в среднем за 2-3 дня, при этом тратится значительное время на их сортировку и анализ (до 1,5 ч в день). Автоматизированный документооборот значительно сокращает время движения ЗРЛ. Процесс ограничивается только временем на внесение информации в программу сбора данных (в среднем 1-2 ч в день). Особенностью разработанной ИС является то, что каждая программа, входящая в состав ИС, работает со своей базой данных, в которой хранятся данные мониторинга и полученных вычислений. Преимущества разработанной ИС: простота работы с программами, 
отсутствие необходимости в высокой квалификации специалистов (достаточно и основных навыков работы с персональным компьютером), способность быстро вносить изменения в программы (язык программирования Delphi прост и широко распространен, как и язык запросов SQL).

На разработанные программные продукты получены авторские свидетельства программ на ЭВМ [8-10]. Для надежной работы программ необходима ЭВМ с параметрами: OC Windows XР или выше, процессор Intel Pentium/Celeron 1800 МГц и выше, оперативная память 512 Мбайт и выше, SVGA дисплей, 150 Мб свободного места на диске.

Отсутствие обоснованных данных и норм надежности ТС затрудняет планирование их эксплуатации, не позволяет прогнозировать отказы элементов ТС. Разработанная ИС дает возможность оценивать и проводить мониторинг показателей надежности функционирования ТC, прогнозировать показатели надежности на основе статистической информации об отказах, консолидируемой в едином информационном пространстве, проектировать дополнительные ступени системы профилактики. Хранение всех данных и результатов вычислений позволят в любой момент вносить изменения в ранее разработанную систему профилактики для совершенствования управления системой технического обслуживания и ремонта ТС.

\section{Список литературы}

[1] Булгаков Н.Ф., Бурхиев Ц.Ц. Управление качеством профилактики АТС. Моделирование и оптимизация. Красноярск: КГТУ, 2002. 164 с.

[2] Булгаков Н.Ф., Коваленко В.В. // Журнал СФУ. Техника и технологии. 2013 (6). № 2. 203-210.

[3] Блянкинштейн И.М., Воеводин Е.С., Худяков Д.А. // Транспорт на альтернативном топливе. 2012. № 3. С. 27-29.

[4] Блянкинштейн И.М. // Мир транспорта и технологических машин. 2012. № 2. С. 133142 .

[5] Кузнецов А.С., Ченцов С.В., Царев Р.Ю. Многоэтапный анализ архитектурной надежности и синтез отказоустойчивого программного обеспечения сложных систем. Красноярск: Изд-во СФУ, 2013. 143 с.

[6] Поляков А.С., Скороходов Д.А. // Вестник Санкт-Петербургского университета государственной противопожарной службы. 2013. № 3. URL: http://vestnik.igps.ru/wp-content/uploads/ V53/12.pdf.

[7] Катаргин В.Н., Коряги М.Е., Морозов Д.А. // Грузовое и пассажирское автохозяйство. 2012. № 1. C. 59-62.

[8] Булгаков Н.Ф., Коваленко В.В., Шалимов С.Н. Модель автоматизированного управления информационным обеспечением системы профилактики // Свидетельство о гос. рег. программы для ЭВМ № 2007613059 от 06.07.2010.

[9] Булгаков Н.Ф., Коваленко В. В., Сиренко Л.Н., Сысоев М.А. Модель статистического оценивания характеристик надежности и эффективности техники // Свидетельство о гос. рег. программы для ЭВМ № 2010614370 от 17.07.2007.

[10] Булгаков Н.Ф., Коваленко В.В., Сиренко Л.Н. Модель проектирования регламента профилактики // Свидетельство о гос. рег. программы для ЭВМ № 2009612900 от 04.06.2009.

$$
-947-
$$

